\title{
Implications of the 2021 ESC cardiovascular risk classification among 283,000 European immigrants living in a low-risk region: a population-based analysis in Catalonia
}

Emili Vela1,2, Montse Cleries ${ }^{1,2}$, Usama Bilal ${ }^{3}$, Maciej Banach4, John W. McEvoy ${ }^{5,6}$, Martin Bødtker Mortensen ${ }^{7,8}$, Michael Joseph Blaha ${ }^{8,9}$, Khurram Nasir ${ }^{8,10,11}$, Josep Comin-Colet ${ }^{12,13,14}$, Josepa Mauri ${ }^{14,15}$, Miguel Cainzos-Achirica ${ }^{8,10,14}$

${ }^{1}$ Healthcare Information and Knowledge Unit, Catalan Health Service, Barcelona, Spain ${ }^{2}$ Digitalization for the Sustainability of the Healthcare System (DS3), Sistema de Salut de Catalunya, Barcelona, Spain

${ }^{3}$ Urban Health Collaborative, Drexel Dornsife School of Public Health, Philadelphia (PA), USA

${ }^{4}$ Department of Hypertension, Chair of Nephrology and Hypertension, Medical University of Lodz (MUL), Lodz, Poland

${ }^{5}$ National University of Ireland and National Institute for Preventive Cardiology, Galway, Ireland

${ }^{6}$ Division of Cardiology, Department of Medicine, Saolta University Healthcare Group, University College Hospital Galway, Galway, Ireland

${ }^{7}$ Department of Cardiology, Aarhus University Hospital, Aarhus, Denmark ${ }^{8}$ Ciccarone Center for the Prevention of Cardiovascular Disease, Division of Cardiology, Johns Hopkins University School of Medicine, Baltimore (MD), USA ${ }^{9}$ Welch Center for Prevention, Epidemiology, and Clinical Research, Johns Hopkins University, Baltimore (MD), USA

${ }^{10}$ Division of Cardiovascular Prevention and Wellness, Department of Cardiology, Houston Methodist DeBakey Heart \& Vascular Center, Houston (TX), USA

${ }^{11}$ Center for Outcomes Research, Houston Methodist, Houston (TX), USA

${ }^{12}$ Department of Cardiology, Bellvitge University Hospital, L'Hospitalet de Llobregat, Barcelona, Spain

${ }^{13}$ Bellvitge Biomedical Research Institute (IDIBELL), L'Hospitalet de Llobregat, Barcelona, Spain

${ }^{14} \mathrm{Pla}$ Director de Malalties Cardiovasculars, Health Department of the Government of Catalonia, Catalonia, Spain

${ }^{15}$ Department of Cardiology, Hospital Universitari Germans Trias i Pujol, Badalona, Spain, Spain

Submitted: 5 December 2021; Accepted: 7 December 2021

Online publication: 7 December 2021

Arch Med Sci 2023; 19 (1): 35-45

DOI: https//doi.org/10.5114/aoms/144631

Copyright $\odot 2021$ Termedia \& Banach

\section{Abstract}

Introduction: The ESC recently classified European countries into 4 cardiovascular risk regions. However, whether Europeans from higher-risk countries living in lower-risk regions may benefit from intensive cardiovascular prevention efforts is unknown. We described the burden of risk factors and cardiovascular disease (CVD) among European-born immigrants living in Catalonia, a low-risk region.

Material and methods: A retrospective cohort study of 5.6 million adults of European origin living in Catalonia in 2019, including 282,789 European-born immigrants, was performed. We used the regionwide healthcare database and classified participants into 5 groups: low-, moderate-, high-, and very high-risk, and local-born. Age-standardized prevalence was estimated as of December 31 $1^{\text {st }}, 2019$ and incidence was computed during 2019 among at-risk individuals.
Corresponding author: Miguel Cainzos-Achirica MD, $\mathrm{MPH}, \mathrm{PhD}$

Division of

Cardiovascular Prevention and Wellness Department of Cardiology Houston Methodist DeBakey Heart \& Vascular Center Houston (TX), USA Ciccarone Center for the Prevention of Cardiovascular Disease Division of Cardiology Johns Hopkins University School of Medicine Baltimore (MD), USA Pla Director de Malalties Cardiovasculars Health Department of the Government of Catalonia Catalonia, Spain E-mail: mcainzosachirica@ houstonmethodist.org 
Results: The very high-risk group was the largest immigrant group ( $N=136,910 ; 48.4 \%)$, while the high-risk group was the smallest $(N=15,739 ; 5.6 \%)$. These two had the highest burden of coronary heart disease across all groups evaluated, in both men and women. The very high-risk group also had the highest prevalence of hypertension and obesity at young-to-middle age, and the burden of risk factors newly diagnosed during 2019 was highest in high- and very high-risk participants. The mean age at first diagnosis of risk factors and CVD was lower in these groups.

Conclusions: In Catalonia, residents born in high- and very-high-risk European countries are at increased risk of coronary heart disease and newly diagnosed risk factors. Low-risk European countries may consider tailored prevention efforts, early screening of risk factors, and adequate healthcare resource planning to better address the health needs of men and women from higher-risk countries.

Key words: cardiovascular disease, coronary heart disease, Eastern Europe, European, guidelines, hypertension, obesity, risk factors.

\section{Introduction}

The European Society of Cardiology (ESC) recently classified European countries into 4 cardiovascular risk regions: low, moderate, high, and very high risk [1, 2]. This classification is based on age-standardized country-level cardiovascular disease (CVD) mortality rates reported by the World Health Organization (WHO) [1], and is intended to enhance the calibration of risk estimations accounting for region-level differences in CVD risk and mortality.

In a given country, cardiovascular mortality rates are the result of a combination of factors, including country-level socioeconomic determinants of health, culture, risk factor burden, breadth of screening efforts, management of risk factors once detected, and access to and quality of care among individuals with established CVD $[3,4]$. Because many of these factors are contextual, it is unknown whether the ESC risk classification should have implications for the risk assessment and management of Europeans born in higher-risk areas who move to lower-risk countries. Establishing the cardiovascular prevention needs of these groups is important, because in many European nations some of the largest immigration fluxes come from other, typically higher-risk, European countries. In the United Kingdom (UK) there currently live large communities of Romanian and Polish residents [5]; in Germany, individuals of Polish, Russian, and Turkish origin represent the largest immigrant groups [6]; in Spain, people born in Romania comprise the second largest immigrant group [7, 8]; and in Italy, Romania and Albania rank first and second, respectively, as countries of origin among the immigrant population [9].

Catalonia is home to more than $280,000 \mathrm{Eu}$ ropeans born outside of Spain [10]. Availability of exhaustive regionwide healthcare databases allows for a detailed evaluation of the burden of cardiovascular risk factors and CVD in relevant population subgroups, and this information can be used to inform targeted public health interventions, enhanced personalized preventive care, and the allocation of adequate healthcare resources.
The aim of this study was to evaluate the burden of cardiovascular risk factors and CVD among European-born residents living in Catalonia, stratified according to the ESC 2021 regional risk classification $[1,2]$.

\section{Material and methods}

\section{Setting and data source}

The study was conducted in Catalonia, a region in Northeastern Spain with a population of 7.8 million as of year 2020, a strong public healthcare system, and universal healthcare coverage for all residents [11-13]. We used the Catalan Health Surveillance System (CHSS) database, which is the regionwide, automated healthcare database used by the Health Department of the Government of Catalonia for administrative, resource allocation, benchmarking, and other purposes. The database is exhaustive, undergoes frequent quality control checks, and captures data for all residents living in Catalonia, including undocumented immigrants (who also have access to the health system by law). It includes sociodemographic data, information on public healthcare system use, medical diagnoses, and prescribed medications. Medical diagnoses are coded using the International Classification of Diseases, $9^{\text {th }}$ Edition, Clinical Modification (ICD 9-CM), and medications are coded using the Anatomical Therapeutic Chemical system. The CHSS can be linked to other relevant databases, such as the local Census to ascertain country of birth. Our group has previously used the CCHS to study the burden of disease in Asian populations living in Catalonia, and our findings were highly consistent with those from well-established research databases in the UK, such as QResearch and the UK Biobank [14-16].

\section{Study design and population}

This was a retrospective cohort study. We included all adult individuals (i.e., 18 years of age or older as of December $31^{\text {st }}, 2019$ ) from the CHSS who were born in a European country. We clas- 
sified participants into 5 mutually exclusive geographic regions of birth: low-risk, moderate-risk, high-risk, and very high-risk European countries, as defined by the ESC [1, 2]; and local-born (individuals born in Catalonia or elsewhere in Spain; from now on, "locals"). The list of countries included in each group together with the number of individuals from each country is presented in Supplementary Table SI. Although Spain is considered a low-risk country by the $\operatorname{ESC}[1,2]$, the "local" group ( $N=5.3$ million) was evaluated separately so that it could serve as a reference group and did not drive the results for the low-risk stratum.

\section{Outcomes}

We were interested in evaluating the burden of 5 major traditional cardiovascular risk factors and 4 CVDs: diabetes, hypertension, hyperlipidemia, obesity, tobacco use, coronary heart disease (CHD), cerebrovascular disease, atrial fibrillation (AF), and heart failure (HF). Supplementary Table SII presents the specific ICD codes used to identify each of these risk factors and conditions, which were consistent with the definitions previously used by our group and others [14].

\section{Other variables}

The following socioeconomic variables recorded in the CHSS were also used for this analysis: yearly income, receipt of welfare support from the Government, and employment status. These data are updated annually. In the CHSS database income is classified for medication co-payment purposes using four categories: high (annual income >100,000€), moderate (annual income 18,000-100,000€), low (annual income <18,000€ but not receiving welfare support), and very low (individuals receiving welfare support from the government) [17]. Employment status was classified as employed or unemployed, the latter also including retired individuals.

\section{Statistical analysis}

We used population pyramids to describe the age and sex distribution of the study population by region of origin, and computed summary statistics of mean age and sex distribution for each group. We also described the distribution of income and employment status.

Prevalence calculations used all historical information about medical diagnoses available in the CHSS database for each participant as of December $31^{\text {st }}, 2019$. We computed the age-standardized prevalence (in \%) of the 5 risk factors and 4 CVDs of interest, stratified by sex, for each group. The WHO 2000-2025 world standard population was used for this purpose [18]. We also displayed graphically the prevalence of each risk factor and condition for each group, stratified by age and sex, using the following age intervals: 18-30, 30-39, 40-49, 50-59, 60-69, and 70+ years. These results were expressed in number of cases per 1,000.

We also calculated the frequency of newly recorded diagnoses of each of the risk factors and CVDs of interest between January $1^{\text {st }}, 2019$ and December $31^{\text {st }}, 2019$. This was conducted as a proxy of incidence calculations, was restricted to individuals at risk of each condition as of January $1^{\text {st }}$, and was aimed at providing additional information besides the prevalence calculations. Incidence was computed as the number of new cases per 1,000 individuals at risk and was also age-standardized. Analyses of crude incidence stratified by age and sex were also displayed graphically.

We also described the mean age at the time of the first recorded diagnosis of each risk factor and CVD, and this was done both for prevalent and incident conditions. All data management and statistical analyses were conducted using $R$ software.

\section{Research ethics}

The data used for the present analysis had already been collected as part of the standard data collection procedures of the Government of Catalonia and the CHSS database. Only the data scientists in the Healthcare Information and Knowledge Unit of the Catalan Health Service (E.V., M.C.) had access to the raw de-identified data, and generated summary tables for the other investigators. For these reasons, the requirement for informed consent was waived.

\section{Results}

\section{Study participants}

Our analysis included 5,593,753 European-born adults living in Catalonia as of December $31^{\text {st }}, 2019$ : 5,310,964 locals, and 282,789 born in other European countries (Table I and Supplementary Figure S1). The largest non-local group was the very high-risk stratum ( $N=136,910 ; 48.4 \%$ ), followed by the moderate- and low-risk groups, whereas the high-risk group was the smallest one $(N=15,739 ; 5.6 \%)$. Individuals from Romania ( $N=73,839)$, Ukraine $(N=18,460)$, and the Russian Federation $(N=15,149)$ comprised the majority of very high-risk participants. Other countries of origin with a large number of individuals included in the study (>10,000 people each) were Italy, France, the United Kingdom, Germany, and Portugal (Supplementary Table SI).

\section{Sociodemographic characteristics}

The local population had the highest mean age (51.8 years; Table I), followed by the low-risk 
Emili Vela, Montse Cleries, Usama Bilal, Maciej Banach, John W. McEvoy, Martin Bødtker Mortensen, Michael Joseph Blaha, Khurram Nasir, Josep Comin-Colet, Josepa Mauri, Miguel Cainzos-Achirica

Table I. Sociodemographic characteristics of the study participants

\begin{tabular}{|c|c|c|c|c|c|}
\hline Parameter & Local & Low risk & Moderate risk & High risk & Very high risk \\
\hline Number & $5,310,964$ & 53,054 & 77,086 & 15,739 & 136,910 \\
\hline Mean age [years] & $51.8(18.6)$ & $46.4(16.3)$ & $41.9(13.8)$ & $38.9(10.7)$ & $40.9(12.5)$ \\
\hline Women (\%) & $2,756,660$ (51.9\%) & $26,052(49.1 \%)$ & $36,083(46.8 \%)$ & 9,435 (59.9\%) & $76,402(55.8 \%)$ \\
\hline \multicolumn{6}{|l|}{ Income: } \\
\hline High & $65,923(1.2 \%)$ & $1,859(3.5 \%)$ & $1,581(2.1 \%)$ & $90(0.6 \%)$ & $187(0.1 \%)$ \\
\hline Moderate & $2,056,568(38.7 \%)$ & $19,717(37.2 \%)$ & $22,370(29.0 \%)$ & $3,662(23.3 \%)$ & $16,768(12.2 \%)$ \\
\hline Low & $3,027,107$ (57.0\%) & $30,721(57.9 \%)$ & $51,417(66.7 \%)$ & $11,413(72.5 \%)$ & $113,172(82.7 \%)$ \\
\hline Very low & $161,366(3.0 \%)$ & $757(1.4 \%)$ & $1,718(2.2 \%)$ & $574(3.7 \%)$ & $6,783(5.0 \%)$ \\
\hline \multicolumn{6}{|c|}{ Employment status: } \\
\hline Employed & $2,792,803(52.6 \%)$ & $25,381(47.8 \%)$ & $41,047(53.2 \%)$ & $7,732(49.1 \%)$ & $62,355(45.5 \%)$ \\
\hline Unemployed & $345,547(6.5 \%)$ & $3,781(7.1 \%)$ & $7,203(9.3 \%)$ & $2,065(13.1 \%)$ & $18,581(13.6 \%)$ \\
\hline
\end{tabular}

Results are presented as either mean (standard deviation) or number (percentage). All p-values for differences between groups < 0.001 .

group, whereas the moderate-, high-, and very high-risk groups were the youngest (mean ages of 41.9, 38.9, and 40.9 years, respectively). Women were the majority in the local population as well as in the high- and very high-risk groups. The higher the risk of the group, the lower was the average income and the higher was the frequency of unemployment status, with $88 \%$ of participants in the very high-risk group having either low or very low income, and $14 \%$ being unemployed. The pop- ulation pyramids for each of the 5 study groups are presented in Supplementary Figure S2.

\section{Cardiovascular risk factors}

The results for risk factors are summarized in Tables II and III, Figures 1 and 2, and Supplementary Figures S3-S8. In analyses of prevalence, the local population had the highest burden of all 5 cardiovascular risk factors in both men and

Table II. Age-standardized prevalence of cardiovascular risk factors and diseases, by sex and area of origin

\begin{tabular}{|c|c|c|c|c|c|}
\hline Parameter & Local & Low risk & Moderate risk & High risk & Very high risk \\
\hline \multicolumn{6}{|l|}{ Men: } \\
\hline Diabetes & 7.0 & 3.9 & 5.0 & 5.3 & 5.2 \\
\hline Hypertension & 17.0 & 12.2 & 14.3 & 16.9 & 16.7 \\
\hline Hyperlipidemia & 15.3 & 10.2 & 12.1 & 11.9 & 12.5 \\
\hline Obesity & 14.3 & 5.9 & 8.5 & 8.2 & 12.9 \\
\hline Tobacco use & 23.4 & 12.9 & 15.4 & 18.5 & 19.7 \\
\hline Coronary heart disease & 3.3 & 2.9 & 3.3 & 4.5 & 3.6 \\
\hline Cerebrovascular disease & 2.6 & 1.6 & 2.1 & 1.7 & 2.2 \\
\hline Atrial fibrillation & 2.1 & 2.0 & 2.0 & 2.2 & 2.1 \\
\hline Heart failure & 1.3 & 0.8 & 1.1 & 1.3 & 1.1 \\
\hline \multicolumn{6}{|l|}{ Women: } \\
\hline Diabetes & 4.6 & 2.5 & 3.1 & 3.6 & 3.9 \\
\hline Hypertension & 14.0 & 9.9 & 11.6 & 14.9 & 15.4 \\
\hline Hyperlipidemia & 13.1 & 8.8 & 10.0 & 9.5 & 11.0 \\
\hline Obesity & 16.2 & 6.0 & 8.7 & 9.2 & 14.4 \\
\hline Tobacco use & 18.6 & 12.5 & 12.4 & 16.2 & 15.4 \\
\hline Coronary heart disease & 1.3 & 1.1 & 1.2 & 1.9 & 2.1 \\
\hline Cerebrovascular disease & 2.1 & 1.4 & 1.7 & 1.8 & 1.8 \\
\hline Atrial fibrillation & 1.3 & 1.1 & 1.2 & 1.5 & 1.3 \\
\hline Heart failure & 1.0 & 0.6 & 0.7 & 0.9 & 0.8 \\
\hline
\end{tabular}

Results are presented as age-standardized prevalence, as of December $31^{\text {st }} 2019$, in \%. All groups were standardized to the World Health Organization world population for 2000-2025. Cells shaded in grey represent the group with the highest age-standardized prevalence for each risk factor or disease. 
Table III. Age-standardized incidence of cardiovascular risk factors and diseases, by sex and area of origin

\begin{tabular}{|c|c|c|c|c|c|}
\hline Parameter & Local & Low risk & Moderate risk & High risk & Very high risk \\
\hline \multicolumn{6}{|l|}{ Men: } \\
\hline Diabetes & 0.6 & 0.5 & 0.6 & 0.8 & 0.7 \\
\hline Hypertension & 1.7 & 1.8 & 2.1 & 2.7 & 2.7 \\
\hline Hyperlipidemia & 1.3 & 1.1 & 1.3 & 1.4 & 1.3 \\
\hline Obesity & 1.3 & 0.8 & 1.1 & 0.9 & 1.8 \\
\hline Tobacco use & 1.6 & 1.5 & 1.8 & 2.3 & 2.2 \\
\hline Coronary heart disease & 0.3 & 0.4 & 0.4 & 0.8 & 0.5 \\
\hline Cerebrovascular disease & 0.4 & 0.3 & 0.3 & 0.1 & 0.3 \\
\hline Atrial fibrillation & 0.3 & 0.3 & 0.3 & 0.3 & 0.4 \\
\hline Heart failure & 0.3 & 0.2 & 0.3 & 0.2 & 0.2 \\
\hline \multicolumn{6}{|l|}{ Women: } \\
\hline Diabetes & 0.4 & 0.3 & 0.4 & 0.3 & 0.6 \\
\hline Hypertension & 1.3 & 1.2 & 1.7 & 1.9 & 2.8 \\
\hline Hyperlipidemia & 1.0 & 0.9 & 1.2 & 0.7 & 1.2 \\
\hline Obesity & 1.3 & 0.7 & 1.0 & 1.3 & 2.0 \\
\hline Tobacco use & 1.0 & 1.0 & 1.1 & 1.3 & 1.3 \\
\hline Coronary heart disease & 0.1 & 0.1 & 0.1 & 0.2 & 0.3 \\
\hline Cerebrovascular disease & 0.3 & 0.3 & 0.2 & 0.5 & 0.3 \\
\hline Atrial fibrillation & 0.2 & 0.2 & 0.2 & 0.2 & 0.3 \\
\hline Heart failure & 0.2 & 0.1 & 0.2 & 0.1 & 0.2 \\
\hline
\end{tabular}

Results are presented as age-standardized incidence, during the year 2019, in \%. All groups were standardized to the World Health Organization world population for 2000-2025. Cells shaded in grey represent the group with the highest age-standardized incidence for each risk factor or disease.

women, except for hypertension among women, the prevalence of which was highest in the very high-risk group (15.4\%; Table II). Focusing on the 4 immigrant groups evaluated, either the high- or the very high-risk groups had the highest burden of all risk factors evaluated in both men and women, while the low-risk group consistently had the lowest prevalence, except for tobacco use among women. In analyses stratified by age, the very high-risk group had the highest prevalence of hypertension between ages 30 and 60 years among men (ages 40-60 for obesity) and between ages 40 and 70 years among women (ages $50-70$ for obesity) (Figure 1).

In analyses of incidence, the high-risk and very high-risk groups had the highest burden of all 5 risk factors in both men and women, even higher than the local group (Table III). The age-adjusted incidence of hypertension in women from the very high-risk group was $2.8 \%$, compared with $1.3 \%$ in the local-born population.

\section{CVD}

The results for CVD are summarized in Tables II and III, Figure 3, and Supplementary Figures S9$\mathrm{S} 14$. For CHD, men from the high-risk group ranked highest both in terms of prevalence and incidence, followed by the very high-risk group. Among women, the very high-risk group ranked highest, followed by the high-risk group. For instance, the age-adjusted prevalence of CHD among women from the very high-risk group was $2.1 \%$, compared with $1.3 \%$ in local-born women; and this was $0.3 \%$ vs. $0.1 \%$ for incident CHD. In analyses stratified by age, in both men and women differences between groups were larger the older the age (Figure 3). For example, among women $\geq 70$ years of age, the prevalence of $\mathrm{CHD}$ in the very high-risk group was 140 per $1,000,144$ per 1,000 in the high-risk group, and 97 per 1,000 in the local-born group. For the other cardiovascular conditions, differences between groups were smaller, with the low-risk group consistently having the lowest burden of all CVDs.

\section{Mean age at first recorded diagnosis}

The high-risk group consistently had the lowest mean age at the time of the first CHSS-recorded diagnosis for all prevalent and incident cardiovascular risk factors and conditions, except for prevalent tobacco use and incident diabetes (Supplementary Table SIII). The very high-risk group ranked second youngest in 16 out of 18 diagnoses evaluated (or first otherwise) and was remarkably 
Emili Vela, Montse Cleries, Usama Bilal, Maciej Banach, John W. McEvoy, Martin Bødtker Mortensen, Michael Joseph Blaha, Khurram Nasir, Josep Comin-Colet, Josepa Mauri, Miguel Cainzos-Achirica
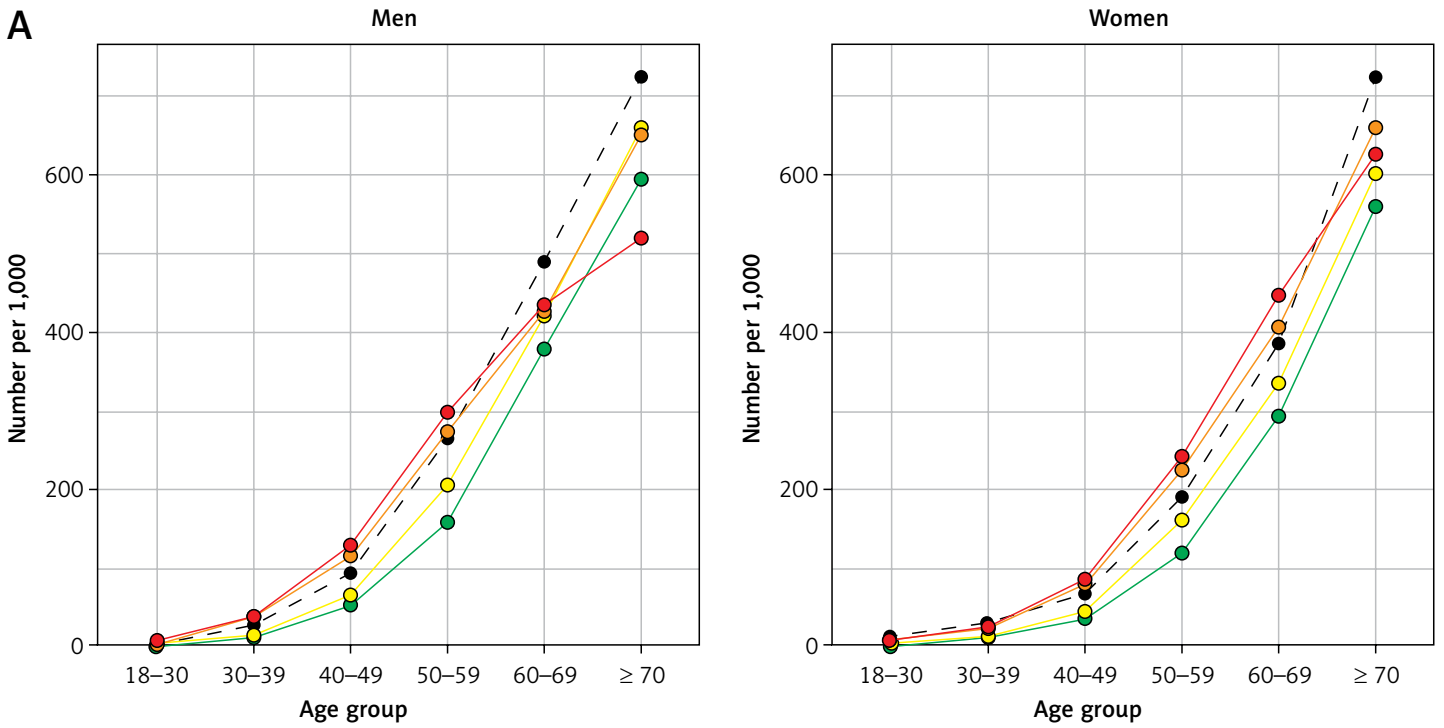

B

Men
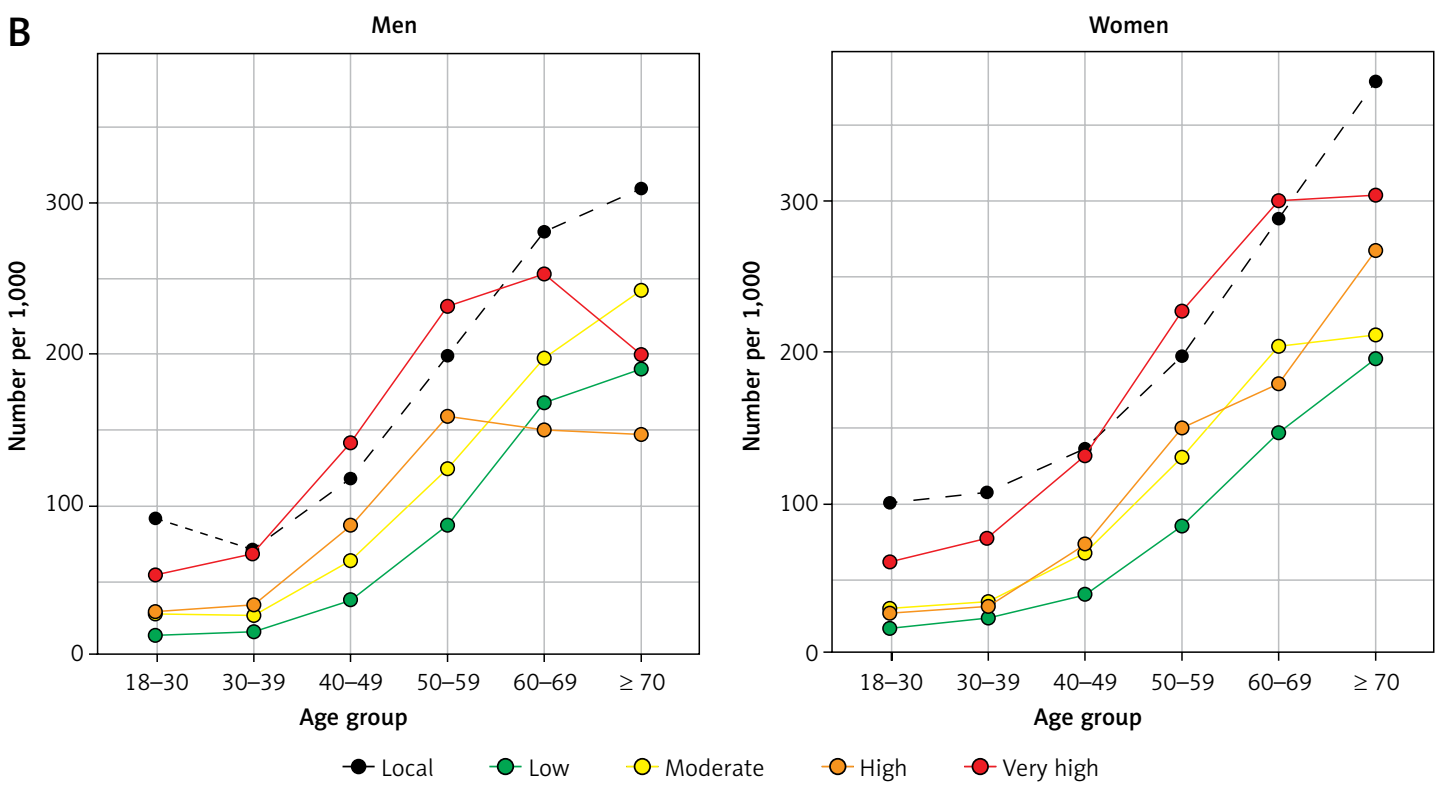

Figure 1. Prevalence of hypertension and obesity by sex, age, and geographic origin, as of December $31^{\text {st }}, 2019$.

A - Hypertension, B - obesity

younger at the time of the first recorded diagnosis than the moderate-risk group, despite a similar mean age ( 40.9 vs. 41.9 years) and a higher proportion of women in the very high-risk group. For instance, compared with individuals in the moderate-risk group, very high-risk participants were on average 6 years younger at the time of the first recording of a prevalent CHD diagnosis, 10 years younger at the time of the first prevalent cerebrovascular disease diagnosis, and 12 years younger at the time of the first HF diagnosis.

\section{Discussion}

Our study followed the publication of the 2021 ESC cardiovascular risk regional classification, and used data for 283,000 European immigrants born outside of Spain and living in Catalonia, as well as for 5.3 million local-born men and women. Our findings have important implications for understanding the cardiovascular health and prevention needs of individuals born in high- and very highrisk European countries who live in lower-risk regions, such as Catalonia. Several European nations have increasingly multi-national, multi-ethnic populations [5-10], and the ESC 2021 prevention guidelines recommended taking into consideration both regional differences within Europe and ethnicity for a more accurate cardiovascular risk assessment [2]. In this context, our findings can help inform more effective cardiovascular public health strategies in countries with large European immigrant communities, and more tailored cardiovascular risk screening, assessment, and management approaches. 
A

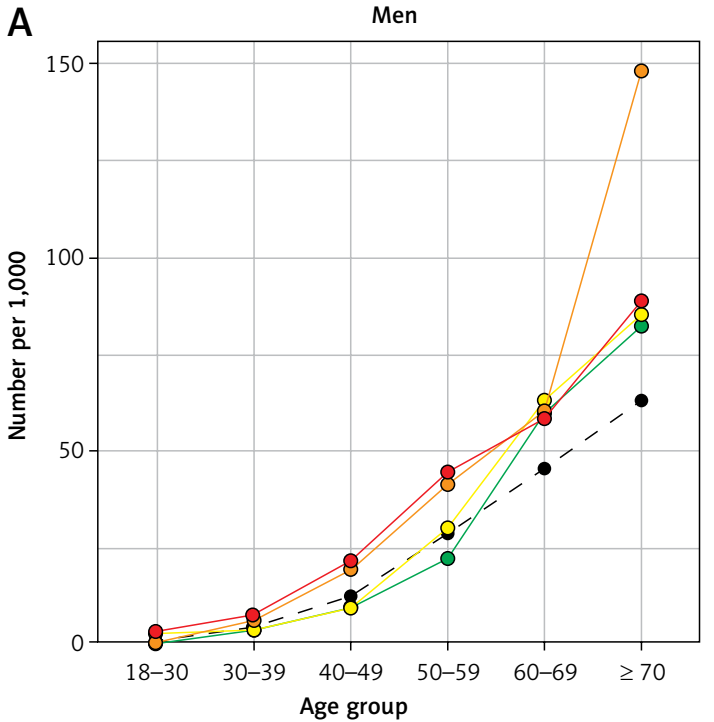

B

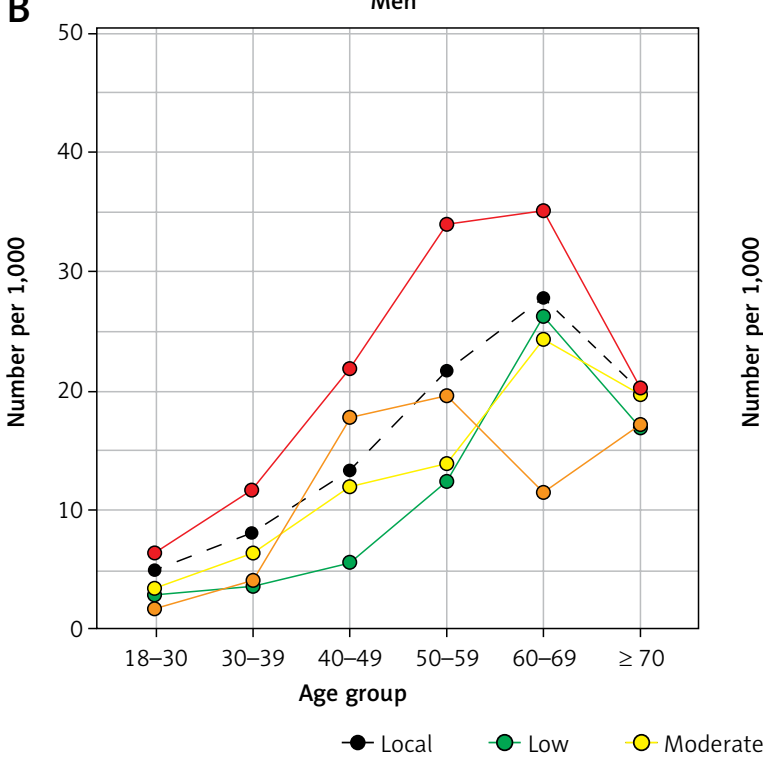

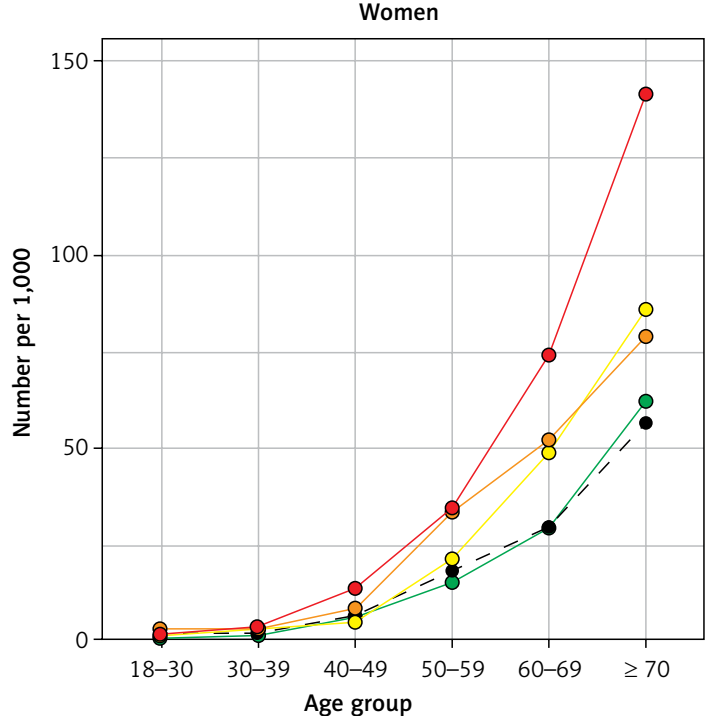

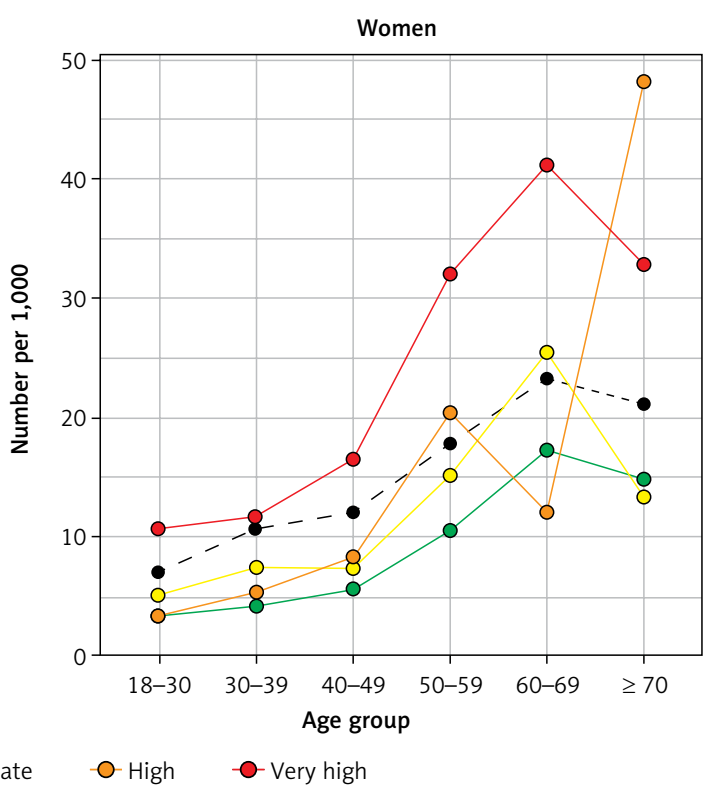

Figure 2. Incidence of hypertension and obesity by sex, age, and geographic origin, January $1^{\text {st }}$ to December $31^{\text {st }}$, 2019. A - Hypertension, B - obesity

Differences between the local-born population and the moderate-risk group were small. Potential explanations of this include: 1) the already modest differences in CVD mortality between the lowand moderate-risk regions defined by the ESC [1, $2], 2)$ the healthy worker selection often associated with migration [19], and 3) acculturation to a Mediterranean lifestyle among individuals born in non-Mediterranean moderate-risk countries (e.g., from Scandinavian countries and Germany) $[20,21]$. It is also possible that a less frequent use of the public healthcare system among certain immigrant groups [22], the limited cumulative historical information in the CHSS database among immigrants compared with local-borns, and the resulting under-detection/under-recording of conditions may have resulted in the underestimation of prevalent risk factors and CVD. However, this would be expected to be less of an issue for incidence estimations of severe acute conditions, such as myocardial infarctions and strokes; and differences between local-borns and the moderate-risk group were also small for these. Our findings suggest that standard cardiovascular prevention approaches and care in low-risk regions such as Catalonia should suffice when caring for European immigrants born in moderate-risk countries who move to lower-risk regions, with no compelling evidence of specific additional needs in this group. The same is true for individuals born in other low-risk European countries.

In contrast, individuals from high- and very high-risk European countries had a higher burden of CHD than the local population and the other 
Emili Vela, Montse Cleries, Usama Bilal, Maciej Banach, John W. McEvoy, Martin Bødtker Mortensen, Michael Joseph Blaha, Khurram Nasir, Josep Comin-Colet, Josepa Mauri, Miguel Cainzos-Achirica
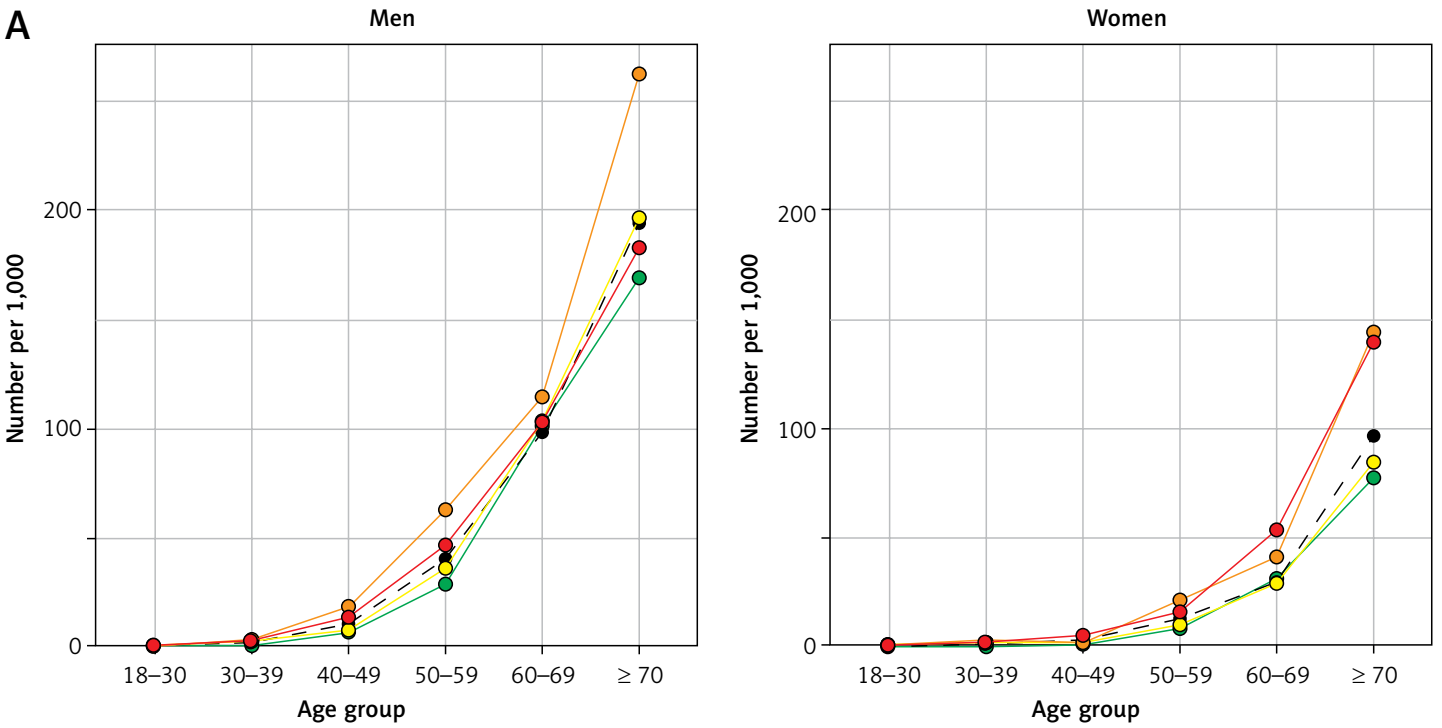

B

Men
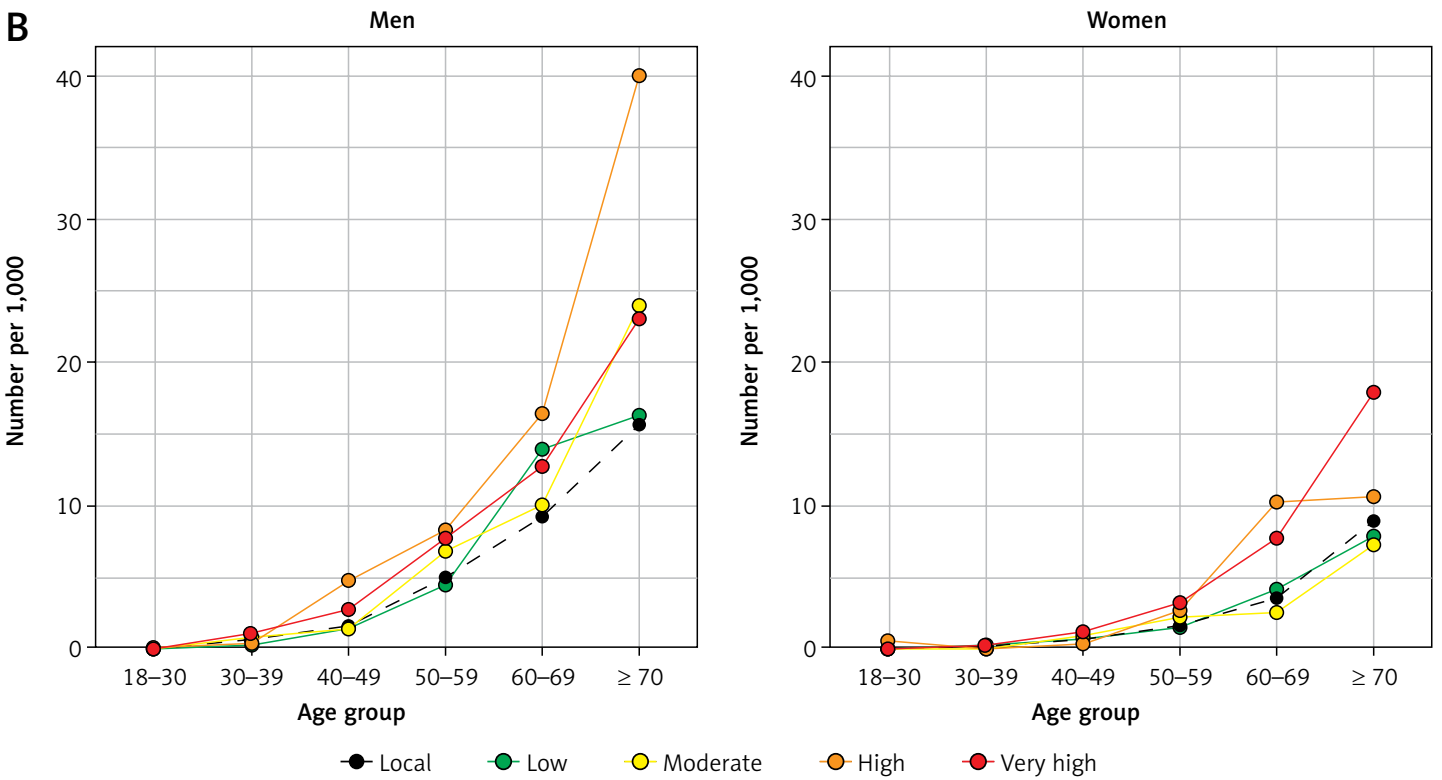

Figure 3. Prevalence of coronary heart disease as of December $31^{\text {st }}, 2019$ and incidence between January $1^{\text {st }}$ and December $31^{\text {st }}, 2019$; by sex, age, and geographic origin. A - Prevalence, B - incidence

immigrant groups. Relative differences were larger among women, in the context of local women having a very low burden of CHD. Moreover, the highand very high-risk groups ranked highest in newly recorded diagnoses during 2019, not only for CHD but also for all risk factors evaluated. Furthermore, the age at first recording of a CHD diagnosis in the CHSS database was remarkably lower among individuals from high- and very high-risk European countries than in the other groups, and the same was true for all risk factors and all other CVDs evaluated. Importantly, this trend was also present in comparisons with the moderate-risk group, which had a similar mean age to the very high-risk group and a significantly higher proportion of men.

The high- and very high-risk groups comprised Eastern Europe, the Balkan peninsula, the Baltic countries, and Turkey (54\% of all non-local study participants) [1, 2]. In our study population, most of these participants were born in Romania, Ukraine, and the Russian Federation. An intuitive explanation for the higher burden of CHD in these groups is the higher rates of cardiovascular risk factors such as hypertension, obesity, diabetes, and hyperlipidemia, or tobacco use reported in Eastern compared with Western European countries [23-26]. While our observations for prevalent risk factors were not consistent with this (except for hypertension among women), under-detection and under-recording may have contributed to the lower burden observed in all immigrant groups compared with the local population. Nonetheless, individuals from high- and very high-risk European countries had the highest burden of prev- 
alent risk factors across the 4 immigrant groups evaluated, and the results for newly recorded risk factors during 2019 are compelling, and overall qualitatively consistent with the findings from multi-national studies [1, 2, 23-26].

The upstream causes leading to a higher burden and earlier presentation of CHD among individuals born in high- and very high-risk European countries are likely multifactorial. Many socioeconomic indicators associated with higher CHD burden tend to be more adverse in Eastern countries and the Balkans than in Central, Northern, and Western Europe [3, 27]. Also, immigrants from high- and very high-risk countries often face adverse work and life conditions in their new home country. Our observations for average income levels and employment status are consistent with this notion. The healthcare systems of Romania and Ukraine rank relatively low in several indices $[12,28]$, and this may have implications for risk factor detection and management, including among individuals who later move to other countries. In terms of lifestyles, according to the WHO the proportion of adults with sufficient levels of physical activity is lower in Romania than in Spain or the United Kingdom [29]. With regards to diets, in the recent Health, Alcohol and Psychosocial factors in Eastern Europe (HAPIEE) study conducted in Russia, Poland, and the Czech Republic, greater adherence to the traditional Eastern European dietary pattern was associated with higher CVD mortality in analyses adjusted for various socioeconomic factors [30]. Dairy products, eggs, potatoes, and lard were typical components of this dietary pattern and had the strongest associations with CVD death [30].

Alcohol intake is also believed to be an important upstream lifestyle cardiovascular risk factor in Eastern Europe [31, 32]. Unfortunately, detailed information on alcohol intake was not available in our database. Finally, meteorological and geomagnetic factors are also considered to play a role in CVD occurrence in countries such as Russia, although these are thought to be more relevant triggering strokes than CHD events [33], and their importance would be expected to be smaller among Russians who move to other regions. More research is needed to better define the upstream factors affecting the burden of CHD among men and women from high- and very high-risk areas who live elsewhere.

Our study has important public health implications. Men and women born in countries such as Romania, Ukraine, and Russia represent some of the largest immigrant groups not only in Catalonia, but also in other Spanish regions $[7,8]$, and in other European countries such as the UK [5], Germany [6], or Italy [9]. In those countries, development of tailored, culturally adapted public health and individual-level preventive interventions adapted to their needs and specific risk profile can help forestall the development of risk factors such as hypertension and obesity, and ultimately of CHD, in these groups. Importantly, recent primordial and primary prevention interventions such as introduction of healthier diets have proven effective in reducing CHD rates in countries such as Poland [34], and similar interventions could be tested among higher-risk groups living in low-risk regions.

\section{Study limitations}

The potential challenges of using a database such as the CHSS when evaluating the health of immigrant groups have been discussed extensively, both above and elsewhere $[14,35]$. Despite these challenges, our analysis was able to confirm a higher burden of CHD in participants from the high- and very high-risk groups, with important implications moving forward. We have also provided reassurance regarding the fact that the number of undocumented immigrants who would not be detected in the CHSS database is expected to be low in Catalonia given universal healthcare coverage, including for undocumented immigrants [14, 22, 35].

The generalizability of our findings to other countries is unknown. Nevertheless, recent analyses in Catalonia using the CHSS database focused on Asian populations yielded remarkably consistent findings with those observed in the UK [14-16]. This provides further reassurance with regards to the internal and external validity of our findings. Finally, information on length of stay in Catalonia was not available, which precluded accounting for this variable in the analyses, as well as evaluating the extent and effect of Mediterranean acculturation. Further research is needed in this field.

In conclusion, in Catalonia, residents born in high- and very high-risk European countries have a higher burden of CHD than the local-born population. This is particularly evident among women in the context of local-born women being at very low risk for CHD. Hypertension and obesity are frequent risk factors among participants from high- and very high-risk European countries, and often develop at young ages. Our findings provide further support for the cardiovascular risk classification used in the 2021 ESC guidelines, and have implications for lower-risk areas receiving large influxes of men and women from high- and very high-risk European countries. Specifically, our study may be used to inform tailored cardiovascular public health campaigns, adapted early screening of risk factors, and healthcare resource planning. 


\section{Acknowledgments}

This research received no specific grant from any funding agency in the public, commercial, or not-for-profit sectors. U.B. received support from the National Institute of Health under grant DP5OD26429.

\section{Conflict of interest}

The authors declare no conflict of interest.

\section{References}

1. SCORE2 working group and ESC Cardiovascular risk collaboration. SCORE2 risk prediction algorithms: new models to estimate 10-year risk of cardiovascular disease in Europe. Eur Heart J 2021; 42: 2439-54.

2. Visseren FLJ, Mach F, Smulders YM, et al.; ESC Scientific Document Group. 2021 ESC Guidelines on cardiovascular disease prevention in clinical practice. Eur Heart J 2021; 42: 3227-337.

3. Rose G. The strategy of preventive medicine. Oxford University Press, Oxford 1992.

4. Patel SA, Winkel M, Ali MK, Narayan KM, Mehta NK. Cardiovascular mortality associated with 5 leading risk factors: national and state preventable fractions estimated from survey data. Ann Intern Med 2015; 163: 245-53.

5. Office for National Statistics. Statistical bulletin: Migration Statistics Quarterly Report: August 2020. https:// www.ons.gov.uk/peoplepopulationandcommunity/populationandmigration/internationalmigration/bulletins/ migrationstatisticsquarterlyreport/august2020 (20 September 2021).

6. Statistisches Bundesamt. Bevölkerung und Erwerbstätigkeit. https://www.destatis.de/DE/Publikationen/ Thematisch/Bevoelkerung/MigrationIntegration/Migrationshintergrund2010220157004.pdf? blob=publicationFile (20 September 2021).

7. Encuesta de Población Activa. Rumanos en España. Padrón municipal 2021, cifras de población. https://epa.com. es/padron/rumanos-en-espana/ (20 September 2021).

8. Instituto Nacional de Estadística. Estadística del Padrón Continuo. Datos provisionales a 1 de Enero de 2021. Comunidades autónomas y provincias. Población extranjera por nacionalidad y sexo. https://www.ine.es/jaxi/ Datos.htm?path=/t20/e245/p04/provi/l0/\&file=0ccaa002.px (20 September 2021).

9. Comuni-Italiani.it. Stranieri per Nazionalità. http:// www.comuni-italiani.it/statistiche/stranieri/ (20 September 2021)

10. Generalitat de Catalunya. La immigració en xifres. http:// treballiaferssocials.gencat.cat/web/.content/03ambits tematics/05immigracio_refugi/dades_immigracio/immigracio_en_xifres/La_immigracio_en_xifres_01-General.pdf (20 September 2021).

11. Instituto Nacional de Estadistica. Cifras oficiales de población resultantes de la revisión del Padrón municipal a 1 de enero. Población por comunidades y ciudades autónomas y tamaño de los municipios. https://www. ine.es/jaxiT3/Datos.htm?t=2915 (20 September 2021).

12. Tandon A, Murray CJL, Lauer JA, Evans DB. World Health Organization. Measuring Overall Health System Performance For 191 Countries. https://www.who.int/healthinfo/paper30.pdf (20 September 2021).

13. Agencia Estatal Boletin Oficial del Estado. Ley 9/2017, de 27 de junio, de universalización de la asistencia san- itaria con cargo a fondos públicos mediante el Servicio Catalán de la Salud. https://www.boe.es/buscar/act. php?id=BOE-A-2017-8524 (20 September 2021).

14. Satish P, Vela E, Bilal U, et al. Burden of cardiovascular risk factors and disease in five Asian groups in Catalonia: a disaggregated, population-based analysis of 121 000 first-generation Asian immigrants. Eur J Prev Cardiol 2022; 29: 916-24.

15. Hippisley-Cox J, Coupland C, Brindle P. Development and validation of QRISK3 risk prediction algorithms to estimate future risk of cardiovascular disease: prospective cohort study. BMJ 2017; 357: j2099.

16. Patel AP, Wang M, Kartoun U, Ng K, Khera AV. Quantifying and understanding the higher risk of atherosclerotic cardiovascular disease among south asian individuals: results from the UK Biobank Prospective Cohort Study. Circulation 2021; 144: 410-22.

17. Bilal U, Cainzos-Achirica M, Cleries $M$, et al. Socioeconomic status, life expectancy and mortality in a universal healthcare setting: an individual-level analysis of $>6$ million Catalan residents. Prev Med 2019; 123: 91-4.

18. NIH. National Cancer Institute. World (WHO 2000-2025) Standard.https://seer.cancer.gov/stdpopulations/world. who.html (20 September 2021).

19. Picciotto S, Hertz-Picciotto I. Commentary: healthy worker survivor bias: a still-evolving concept. Epidemiology 2015; 26: 213-5.

20. Estruch R, Ros E, Salas-Salvadó J, et al.; PREDIMED Study Investigators. Primary prevention of cardiovascular disease with a mediterranean diet supplemented with extra-virgin olive oil or nuts. N Engl J Med 2018; 378: e34.

21. Martínez-González MA, Gea A, Ruiz-Canela M. The Mediterranean diet and cardiovascular health. Circ Res 2019; 124: 779-98.

22. Dalmau-Bueno A, García-Altés A, Vela E, Clèries M, Pérez $C V$, Argimon JM. Frequency of health-care service use and severity of illness in undocumented migrants in Catalonia, Spain: a population-based, cross-sectional study. Lancet Planet Health 2021; 5: e286-96.

23. Ginter E. The epidemic of cardiovascular disease in Eastern Europe. N Engl J Med 1997; 336: 1915-6.

24. GBD 2016 Lifetime Risk of Stroke Collaborators, Feigin VL, Nguyen G, Cercy K, et al. Global, regional, and country-specific lifetime risks of stroke, 1990 and 2016. N Engl J Med 2018; 379: 2429-37.

25. Dyrbuś K, Osadnik T, Desperak P, Desperak A, Gasior M, Banach M. Evaluation of dyslipidaemia and the impact of hypolipidemic therapy on prognosis in high and very high risk patients through the Hyperlipidaemia Therapy in tERtiary Cardiological cEnTer (TERCET) Registry. Pharmacol Res 2018; 132: 204-10.

26. Deckert A, Winkler V, Paltiel A, Razum O, Becher H. Time trends in cardiovascular disease mortality in Russia and Germany from 1980 to 2007 - are there migration effects? BMC Public Health 2010; 10: 488.

27. Wikipedia. List of sovereign states in Europe by GDP (PPP) per capita. https://en.wikipedia.org/wiki/List_of sovereign_states_in_Europe_by_GDP_(PPP)_per_capita (20 September 2021).

28. World Population Review. Best Healthcare In The World 2021. https://worldpopulationreview.com/country-rankings/best-healthcare-in-the-world\#dataTable (20 September 2021).

29. World Health Organization. Regional Office for Europe. Physical Activity Factsheets For The 28 European Union Member States Of The Who European Region https://www.euro.who.int/ data/assets/pdf 
file/0005/382334/28fs-physical-activity-euro-rep-eng pdf (20 September 2021).

30. Stefler D, Brett D, Sarkadi-Nagy E, et al. Traditional Eastern European diet and mortality: prospective evidence from the HAPIEE study. Eur J Nutr 2021; 60: 1091-100.

31. McKee M, Shkolnikov V, Leon DA. Alcohol is implicated in the fluctuations in cardiovascular disease in Russia since the 1980s. Ann Epidemiol 2001; 11: 1-6.

32. GBD 2016 Alcohol Collaborators. Alcohol use and burden for 195 countries and territories, 1990-2016: a systematic analysis for the Global Burden of Disease Study 2016. Lancet 2018; 392: 1015-35.

33. Shaposhnikov D, Revich B, Gurfinkel Y, Naumova E. The influence of meteorological and geomagnetic factors on acute myocardial infarction and brain stroke in Moscow, Russia. Int J Biometeorol 2014; 58: 799-808.

34. Zatonski WA, Willett W. Changes in dietary fat and declining coronary heart disease in Poland: population based study. BMJ 2005; 331: 187-8.

35. Cainzos-Achirica M, Vela E, Cleries M, et al. Cardiovas cular risk factors and disease among non-European immigrants living in Catalonia. Heart 2019; 105: 1168-74. 